\title{
Review \\ A Strategy for Hospital Pharmacists to Control Antimicrobial Resistance (AMR) in Japan
}

\author{
Yukihiro Hamada ${ }^{1, * \mathbb{D}}$, Fumiya Ebihara ${ }^{1}$ and Ken Kikuchi ${ }^{2}$ \\ 1 Department of Pharmacy, Tokyo Women's Medical University Hospital, Tokyo 162-8666, Japan; \\ ebihara.fumiya@twmu.ac.jp \\ 2 Department of Infectious Disease, Tokyo Women's Medical University Hospital, Tokyo 162-8666, Japan; \\ kikuchi.ken@twmu.ac.jp \\ * Correspondence: hamada.yukihiro@twmu.ac.jp
}

Citation: Hamada, Y.; Ebihara, F.; Kikuchi, K. A Strategy for Hospital Pharmacists to Control Antimicrobial Resistance (AMR) in Japan. Antibiotics 2021, 10, 1284. https:// doi.org/10.3390/antibiotics10111284

Academic Editor: Antonello Di Paolo

Received: 25 September 2021

Accepted: 19 October 2021

Published: 21 October 2021

Publisher's Note: MDPI stays neutral with regard to jurisdictional claims in published maps and institutional affiliations.

Copyright: (C) 2021 by the authors. Licensee MDPI, Basel, Switzerland. This article is an open access article distributed under the terms and conditions of the Creative Commons Attribution (CC BY) license (https:// creativecommons.org/licenses/by/ $4.0 /)$.

\begin{abstract}
In Japan, there is concern regarding the relation between the inappropriate use of antibiotics and antibiotic resistance (AMR). Increased bacterial resistance is due in part to the inappropriate use of antimicrobial agents. The support of the pharmacist becomes important, and there is growing interest in antimicrobial stewardship to promote the appropriate and safe use of antimicrobials needed for the optimal selection of drugs, doses, durations of therapy, therapeutic drug monitoring (TDM), and implementations of cost containment strategies in Japan. Pharmacists should strive to disseminate the concept of "choosing wisely" in relation to all medicines, implement further interventions, and put them into practice. In this article, we present data for antimicrobial stewardship and Japan's AMR action plan, focusing on how pharmacists should be involved in enabling physicians to choose antimicrobials wisely.
\end{abstract}

Keywords: antimicrobial stewardship; antifungal stewardship; strategy of pharmacist; therapeutic drug monitoring; pharmacokinetics/pharmacodynamics

\section{Introduction}

The spread of drug-resistant bacteria poses a serious threat to human beings worldwide [1]. At the 2015 World Health Assembly, the World Health Organization appointed each country to develop a national action plan (NAP) to counter the rise in antimicrobial resistance (AMR) [2]. As of 2018, 115 countries and territories had implemented such plans, with 34 others in the process of developing their own proposals [3]. Japan announced its National Action Plan on Antimicrobial Resistance in April 2016, setting specific goals for a reduction in antimicrobial use by 2020 [4]. There is a background of Japan's inordinately frequent use of broad-spectrum oral antibiotics [5]; its NAP set reduction targets for selected antibiotic categories in addition to total antimicrobial use. These goals included a $33 \%$ reduction in total antimicrobial use; $50 \%$ reductions in oral fluoroquinolone, cephalosporin, and macrolide use; and a $20 \%$ reduction in parenteral antimicrobial use in 2020 relative to 2013. In our hospital research conducted over a period of 2 years, we found significant reductions $(p<0.01)$ in the defined daily doses (DDDs) of oral third-generation cephalosporins and fluoroquinolones. Furthermore, a significant reduction was also found in the total DDDs of the antibiotics used. In addition, the implementation of antimicrobial stewardship reduced the unnecessary antimicrobial prescription rate for acute respiratory tract infections and acute diarrhea (Figure 1) [6].

Infectious disease (ID) pharmacists have to extend their support for the appropriate use of antimicrobials prescribed by attending physicians to not only hospitalized patients but also outpatients. "Choosing wisely", the United States-based health education campaign, warns against the unnecessary use of antimicrobials [7]. Pharmacists are encouraged to promote the concept of "choosing wisely" in relation to other medicines, implement further interventions, and put them into practice. AMR Alliance Japan also suggests that 
efforts should be made to promote an increase in the number of healthcare workers trained to conduct therapeutic drug monitoring (TDM) in the Japanese government's next NAP on AMR, which will be implemented as of 2021 on the basis of a policy recommendation published in July 2019 [8]. In this article, we present data for antimicrobial stewardship in Japan, focusing on methicillin-resistant Staphylococcus aureus (MRSA), candidiasis, and extended-spectrum $\beta$-lactamase (ESBL)-producing Enterobacteriaceae, which are particular problems in hospitals, and we provide suggestions on how pharmacists should practice to enable physicians to choose antimicrobials wisely.

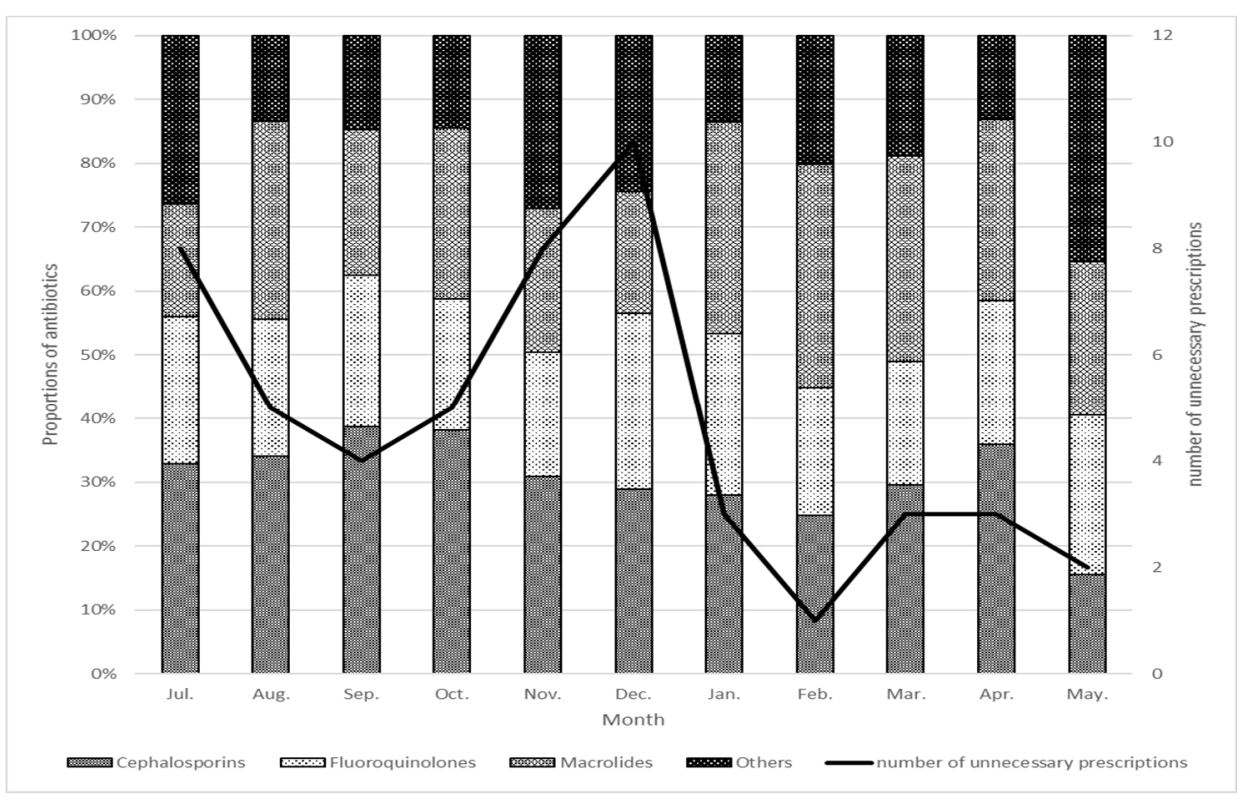

(A)

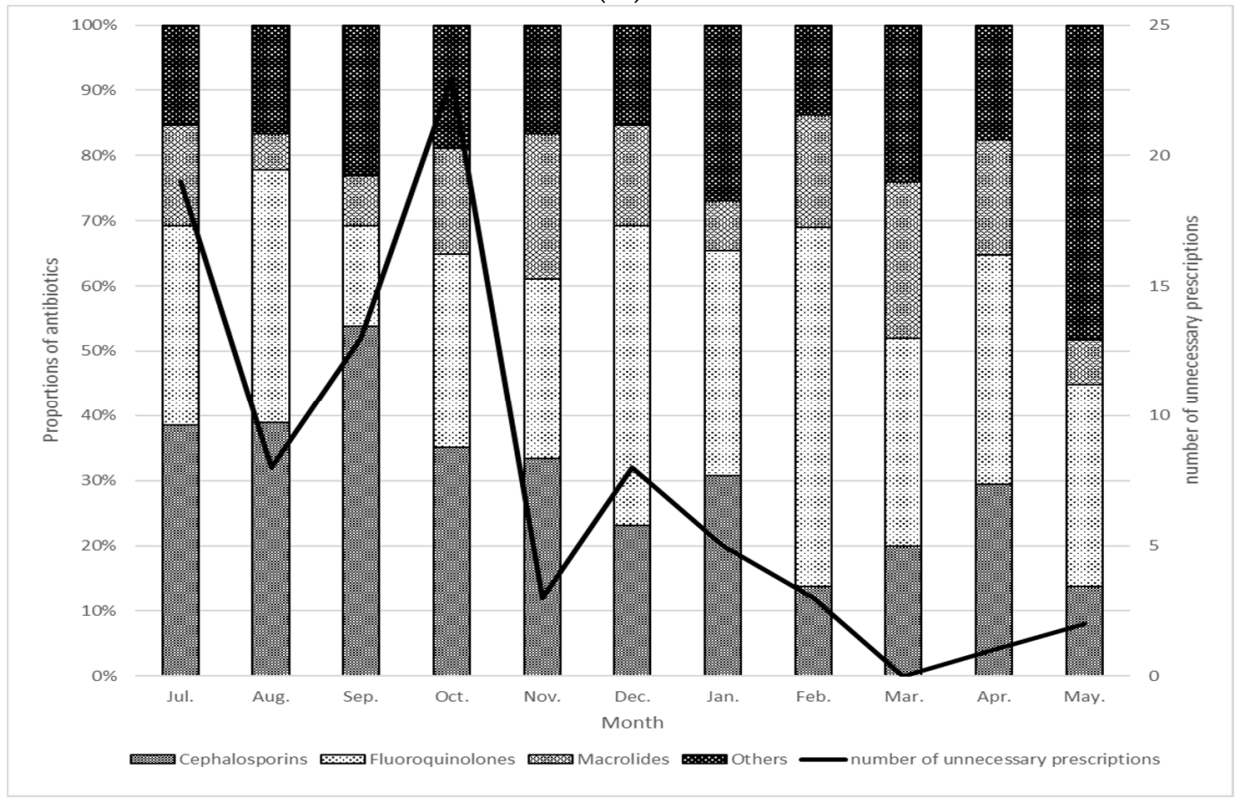

(B)

Figure 1. Distribution of antibiotics prescribed for acute respiratory tract infections (A) and acute diarrhea (B), 7 July 2020-May 2021 [6]. The bar graph shows cumulative percentage of oral antimicrobial agents by category. The line graph shows the change in the number of unnecessary antimicrobial agent prescriptions. (A) Acute respiratory tract infections, (B) Acute diarrhea. 


\section{Antimicrobial Stewardship with MRSA and Extended-Spectrum $\beta$-Lactamase (ESBL)-Producing Enterobacteriaceae}

2.1. Epidemiology of MRSA in Japan

In Japan, the most common AMR organism is MRSA [9]. MRSA is one of the most common bacteria causing healthcare-associated infections and is the most notable resistant bacterium in hospitals.

According to the Japan Nosocomial Infection Surveillance (JANIS) sponsored by the Ministry of Health, Labour, and Welfare, MRSA was isolated from 2162 out of 2167 medical institutions (99.8\%) surveyed in 2020. MRSA previously accounted for 50 to $70 \%$ of Staphylococcus aureus isolates from hospitalized patients, but, in recent years, there has been a decreasing trend [10]. Tsuzuki et al. [11] reported that the number of bloodstream infection (BSI) deaths attributable to S. aureus was expected to be 17,412 in 2011 and 17,157 in 2017, respectively, out of the whole population (126.8 million) in Japan. Among them, the cases attributed to MRSA accounted for $5924(34.0 \%)$ in 2011, and this figure decreased to $4224(24.6 \%)$ cases in 2017 . The number of BSI deaths attributable to MRSA has shown a decreasing trend. Tsuzuki et al. [12] estimated the disease burden of BSI caused by major Japanese antimicrobial-resistant bacteria between 2015 and 2018 in terms of disabilityadjusted life-years (DALYs; [13]). The disease burden due to MRSA in Japan in 2018 was estimated to be 57.8 DALYs per 100,000 population, which was reported to be significantly higher in Japan than in EU/EEA countries (57.8 vs. 20.9 per 100,000 population) [14].

Uematsu et al. [15] analyzed the clinical and economic burdens attributable to methicillin resistance in $S$. aureus in Japanese hospitals. The participants were inpatients from admission on 1 April 2014 to discharge on 31 March 2016. A total of 7188 patients were classified into the MRSA group and 7717 patients into the MSSA group. The outcomes were assessed by the length of hospital stay, inpatient costs, and in-hospital mortality, and the disease burden was compared. The MRSA-group-adjusted effects were 1.03-fold (95\% confidence interval (CI), 1.01-1.05) and 1.04-fold (95\% CI, 1.01-1.06), with an odds ratio of $1.14(95 \% \mathrm{CI}, 1.02-1.27)$. This result shows that the disease burden was higher in the inpatients with MRSA than in those with MSSA; moreover, the attributable burden of methicillin resistance was significant after adjustments.

In Japan, vancomycin, teicoplanin, arbekacin, and linezolid had been used as four therapeutic agents against MRSA. Recently, newer anti-MRSA agents have been approved, including daptomycin in 2011 and tedizolid in 2018 [16]. As a result, it was found that the total anti-MRSA agent use was increased significantly over time. It is thought that this may reflect compliance with the guidelines, the launch of new anti-MRSA drugs, and less promotion of the original agents in Japan. Goto et al. [17] reported on the trends of only anti-MRSA agent use in Japan based on sales data. The total anti-MRSA agent use was found to have significantly increased from 2006 to 2015 ( $p$ for trend $=0.027$ ). The individual trends for arbekacin and teicoplanin showed decreases, while vancomycin, daptomycin, and linezolid use showed significant increases. In addition, there was no significant change in the use of intravenous linezolid, but the use of oral linezolid increased significantly. As a result, the ratio of oral linezolid use to total linezolid use increased from $25.5 \%$ in 2006 to $39.9 \%$ in 2015 . Therefore, we are paying close attention to the amount of oral linezolid used in Japan. On the other hand, arbekacin and teicoplanin use decreased while vancomycin use increased following the launch of generic medicines. These results may reflect compliance with the guidelines, the launch of new anti-MRSA agents, and less promotion of the original agents.

In particular, vancomycin, teicoplanin, and arbekacin were difficult to achieve the target trough concentration with the dose setting in the Japanese package insert. The adequate dosage in compliance with the guidelines may be one factor in the increase in the dosage. The AMR problem might be even more serious in Japan if the dosage was the same as before. 


\subsection{Antimicrobial Stewardship of MRSA by Pharmacists in Japan}

As mentioned earlier, the frequency of MRSA isolation has decreased in Japan in recent years, but MRSA remains the most frequently isolated resistant pathogen. Therefore, the first priority in MRSA infection control is to prevent the spread of MRSA [18], and the thorough implementation of standard precautions, such as hand hygiene, is an effective means of preventing the spread of MRSA in hospitals [19-21]. In addition to measures to prevent the spread of MRSA, the appropriate use of antimicrobial agents is necessary to reduce the risk of MRSA infection. It is desirable to take a proactive approach as an organization by adopting antimicrobial stewardship and collaborating with multiple professions [22,23].

Niwa et al. [24], Japanese pharmacists, reported that antimicrobial stewardship interventions are effective in reducing the inappropriate use of antibiotics, lowering MRSA ratios, shortening hospital stays, and reducing healthcare costs. The prolonged use of antibiotics over 2 weeks was significantly reduced after the active implementation of antimicrobial stewardship ( $2.9 \%$ vs. $5.2 \%, p<0.001)$. A significant reduction in the antimicrobial consumption was observed in aminoglycosides $(p<0.001)$, carbapenems $(p=0.003)$, and second-generation cephalosporins $(p=0.03)$, leading to an $11.7 \%$ reduction in the antibiotic costs. The rate of MRSA decreased significantly from $47.6 \%$ to $39.5 \%(p=0.026)$. Moreover, the average length of hospital stay was shortened by 2.9 days after the active implementation of antimicrobial stewardship.

Ohashi et al. [25], Japanese pharmacists, reported on the impact of antimicrobial stewardship by pharmacist intervention in MRSA bacteremia patients using a treatment bundle. With the intervention of an antimicrobial stewardship team pharmacist, an increase was observed in the appropriate duration of therapy, incidences of the early use of antiMRSA drugs, and the number of negative follow-up blood cultures, and a decrease was observed for 30-day mortality and hospital mortality, with significant differences. A multivariate analysis of these indicated that the intervention group was independent of 30-day mortality and hospital mortality risk reduction factors (odds ratio (OR), $0.33 ; 95 \%$ confidence interval (CI), 0.12-0.86, and OR, 0.20 ; 95\% CI, 0.07-0.53).

In addition to the selection of appropriate antimicrobial agents and the duration of the treatment, the implementation of TDM for anti-MRSA drugs is essential for antimicrobial stewardship.

The "Therapeutic monitoring of vancomycin for MRSA infections: A revised consensus guideline" [26] published by several societies, including the Infectious Diseases Society of America, also sets a target for dosing guided by the target area under the curve (AUC) over $24 \mathrm{~h}$ for clinical efficacy and safety and states that evaluation via trough concentrationguided dosing alone is not recommended in severe MRSA infections. The Japanese TDM guidelines for antimicrobial agents will be revised in 2021, and evaluation by AUC-guided dosing will be recommended.

Our group, Suzuki et al. [27], reported that the risk factors for vancomycin-induced nephrotoxicity were comparable in both trough concentration and/or the AUC. The incidence of nephrotoxicity can be reduced by controlling vancomycin via trough concentrationand AUC-guided dosing as well as promoting antimicrobial stewardship. Clearly, the AUC-guided dosing of vancomycin is important. However, accurate AUC-guided dosing may require multiple blood samples. Therefore, it is important to properly use AUC and/or trough monitoring. AUC-guided dosing is recommended for patients at a high risk of renal impairment, but, for patients without AUC-guided dosing, it is important to build a predictable model even with conventional trough monitoring. Especially under COVID-19, we want to reduce blood sampling points as much as possible, and this result will be one tool for pharmacists to propose TDM to physicians.

In a multicenter study, Hashimoto et al. [28] identified risk factors for early- and late-phase vancomycin-induced acute kidney injury (AKI) to identify candidates for AUCguided dosing, rather than trough concentration (Cmin)-guided dosing, who require a more accurate dose titration to reduce the risk of AKI. AKI was observed in $8.5 \%$ of the 
patients (159/1882). AKI appeared within the first 7 days of therapy (early phase) in the majority of the patients. Important AKI risk factors during the early phase were identified as a Cmin $>20 \mathrm{mg} / \mathrm{L}$, concurrent diuretic or piperacillin/tazobactam use, intensive care unit stay, and pre-existing renal dysfunction. A transiently elevated Cmin (>15-20 mg/L) was not associated with a greater risk of AKI. In patients with the risk factors for AKI, the cut-off $\mathrm{Cmin}$ and the estimated safe $\mathrm{Cmin}$ for reduced AKI risk were $18.8-21.0 \mathrm{mg} / \mathrm{L}$ and $<11.7-13.5 \mathrm{mg} / \mathrm{L}$, respectively. As a result, the patients with AKI risk factors require a low target $\mathrm{Cmin}$. The presence of several risk factors may indicate a need for more accurate dose titration using AUC-guided administration.

Our pharmacists should strive to reduce the patient risk while creating novel evidence for TDM.

\subsection{Anti-Extended-Spectrum $\beta$-Lactamase (ESBL)-Producing Enterobacteriaceae Agents Stewardship Epidemiology of ESBL in Japan}

The use of broad-spectrum antibiotics has increased infections caused by antimicrobialresistant bacteria. The epidemic of these resistant bacteria is a global threat to public health systems [29]. Among these, ESBL-producing Escherichia coli (ESBL E. coli) infections represent the greatest threat [30,31], with the number of infected patients increasing around the world [32,33], especially in Asia, Africa, and Latin America [34]. In addition to its use for humans in clinical practice, far greater amounts of antimicrobials are currently consumed by the animal husbandry sector, including aquaculture. This massive usage is not only for the treatment or prophylaxis of food animals but also for growth promotion purposes [35].

Nishiyama et al. [36] reported on wastewater samples from a municipal wastewater treatment plant and hospital wastewater for six species of antibiotic-resistant bacteria: ESBLproducing Enterobacteria, carbapenem-resistant Enterobacteria (CARBA), multidrug-resistant Acinetobacter (MDRA), multidrug-resistant Pseudomonas aeruginosa (MDRP), methicillinresistant Staphylococcus aureus (MRSA), and vancomycin-resistant Enterococci (VRE). They registered a high percentage of antibiotic-resistant bacteria in the municipal wastewater treatment plant samples $(>66 \%)$ for all the antibiotic-resistant bacteria except for MDRP, indicating a high prevalence in the population. The proportion of hospital wastewater samples was low $(<78 \%)$, and VRE was not detected throughout the study. CARBA and ESBL were detected in all the wastewater samples, and MDRA and MRSA were very abundant in Japan.

ESBLs mediate resistance to third-generation cephalosporins in E. coli and Klebsiella pneumoniae. In general, serious infections caused by these strains are treated with carbapenems. However, if carbapenem is used in all cases, carbapenem resistance may be selected.

The MERINO open-label randomized controlled study has provided clear evidence that piperacillin-tazobactam should be avoided for the targeted therapy of bloodstream infections due to ESBL-producing E. coli and K. pneumoniae, regardless of the patient population, source of infection, bacterial species, and susceptibility result of piperacillintazobactam. The verification of other treatments for mild infections with ESBL may not yet be sufficiently validated [37]. Data on the clinical efficacy of new drugs specific to infections caused by carbapenem-resistant pathogens are gradually being published. It seems to favor newer drugs rather than previously available treatments.

As more treatment options become widely available for carbapenem-resistant, Gramnegative infections, the role of antimicrobial stewardship will become crucial in ensuring the appropriate and rational use of these new agents [38].

Postmenopausal women in Japan have an increased proportion of ESBL E. coli and lower susceptibility to LVFX. The ESBL E. coli isolates appeared to have a high susceptibility to tazobactam-piperacillin, cefmetazole, carbapenems, aminoglycosides, and fosfomycin [39].

Nakai et al. [40] reported that the problem of ESBL production includes not only nosocomial infections but also community-acquired infections. Antimicrobial usage (for more 
than 4 days) during the preceding 60 days was a risk factor, especially the usage of aminoglycoside, oxazolidinone, tetracycline, fluoroquinolone, trimethoprim/sulfamethoxazole, and second- and fourth-generation cephalosporin [40]. Japanese pharmacists need to consider the background and treatment strategies.

\subsection{Antimicrobial Stewardship of ESBL by Pharmacists in Japan}

Pharmacists play an important role in antimicrobial stewardship, including optimizing the treatment of multidrug-resistant pathogens. It is estimated that up to $50 \%$ of hospital prescriptions for antibiotics are unnecessary [41]. Recently, the development of antibiotics has slowed considerably, and the options for treating increasingly resistant infections have become increasingly limited [42]. This is also the case in Japan. It is important for the pharmacist to recognize ESBL-producing pathogens and understand which antibiotics are supported by the strongest data and outcomes. The pharmacist should be aware of the source of infection and the treatment options available. Additionally, pharmacists can implement antimicrobial stewardship throughout the healthcare system, such as avoiding the unnecessary administration of antibiotics and de-escalating use as soon as possible, which can help prevent patients from developing resistant pathogens. Antimicrobial stewardship can provide pharmacists with the information they need to avoid the overuse of antibiotics and to help prevent the development of forms of antimicrobial resistance, such as ESBLs [43].

Kusama et al. [44] reported that the National Action Plan on Antimicrobial Resistance significantly reduced antimicrobial use in Japan. This plan resulted in both an immediate and accelerated reduction in antimicrobial use. Antimicrobial use reductions of $15.0 \%$ for total antimicrobials, $26.3 \%$ for cephalosporins, $24.6 \%$ for macrolides, and $23.5 \%$ for fluoroquinolones were predicted for 2020 relative to 2013. While Japan's National Action Plan has contributed to the reduction in national antimicrobial use over the past 5 years, sustainable action is still needed to continue to improve antimicrobial stewardship and promote countermeasures to antimicrobial resistance.

As reported by a group of Japanese pharmacists, Kato et al. [45], a combination of prescription support activities and oral antimicrobial treatment reporting systems is an effective way to facilitate the use of appropriate antimicrobial agents. These authors evaluated preauthorization, a prospective audit, and a feedback system. The total annual amount of oral third-generation cephalosporin usage decreased significantly over time between the phases. During the same period, the incidence rate of MRSA, ESBLs, and AmpC $\beta$-lactamase (AmpC)-producing bacteria was not changed significantly, indicating that oral third-generation cephalosporin usage was reduced without a concomitant increase in the drug-resistant bacteria.

The rate of urinary tract infections caused by ESBLs has increased worldwide. The development of new antibiotics that are effective against ESBL E. coli is undoubtedly a top health care priority by the World Health Organization [46]. The cefmetazole of cephamycin is stable against the hydrolysis by ESBLs and has robust in vitro activity with lower minimum inhibitory concentrations (MICs) against ESBL E. coli isolates [47]. Therefore, cefmetazole is receiving increasing interest as a potential carbapenem-saving treatment option for ESBL infections. Cefmetazole and flomoxef are commonly used in Japan as they are expected to have therapeutic effects [48,49]. As the evidence, a few observational studies have examined the efficacy of cephamycin against ESBL E. coli infection. Doi et al. reported that the efficacy of cefmetazole against ESBL E. coli for UTI was similar to that of carbapenems (90\%) without major adverse events [50]. Another study included patients with ESBL $E$. coli bacteremia who were treated with a carbapenem $(n=43)$ or cefmetazole $(n=26)$ and reported comparable mortality rates in the two groups [51]. In both studies, the majority ( $>90 \%$ ) of ESBL E. coli included in the analyses comprised ESBLs. Unfortunately, the dosage and usage of cefmetazole was not described in the reports.

Therefore, Hamada et al. [52], our group of Japanese pharmacists, retrospectively evaluated the dose adjustment by renal function with the administration of various doses. 
The extension in infusion time from $0.5 \mathrm{~h}$ to $1 \mathrm{~h}$ is a feasible practice in clinical settings and recommended strategy when administering cefmetazole. In conclusion, $1 \mathrm{~g}$ of cefmetazole infused for over $1 \mathrm{~h}$ every $8 \mathrm{~h}$ proved to be efficacious for the treatment of UTI caused by ESBL E. coli with cefmetazole MIC $\leq 4 \mathrm{mg} / \mathrm{L}$ in PK/PD theory. This PK/PD relationship finding can be applied as a foundation for future clinical studies addressing the utility of cefmetazole or other antimicrobial agents as a carbapenem-sparing treatment option for ESBL E. coli infections.

The strategies of these pharmacists can play an essential role in assisting providers with the selection of appropriate antimicrobial agents for these multidrug-resistant pathogens in order to improve patient outcomes.

\section{Antifungal Stewardship}

\subsection{Epidemiology of Fungal Infections in Japan}

In recent years, the prevalence of invasive candidiasis has increased with the advancement of medicine, representing an important complication. In the United States, Candida is now the fourth most common pathogenic microorganism in nosocomial bloodstream infections [53]. Although there are few epidemiological studies in Japan, the breakdown of blood borne isolates reported by the JANIS shows that the most common Candida albicans of the Candida species was reported to be tenth [9]. The Epidemiological Investigation Committee for Human Mycoses in Japan included a total of 328,318 blood cultures from 2003 to 2014 according to a retrospective epidemiological survey of candidemia and causative Candida species. The prevalence of fungi in all the cultures and in the positive cultures were $0.58 \%$ and $4.46 \%$, respectively, and the frequency of C. albicans has significantly decreased, while that of C. glabrata has increased during the last 6 years in Japan [54].

Kishimoto et al. [55] reported the overall epidemiology of invasive fungal disease (IFD) in Japanese children. The proven or probable of IFD was 26 of 20,079 hospitalized patients $(0.13 \%)$ from 2011 to 2015 . The overall mortality was $23 \%$, and the attributable mortality of IFD was $12 \%$. These results warn of the emergence of non-albicans Candida species as important pathogens in pediatric IFD.

In 20 years, the number of treatment options for invasive fungal infections has increased in Japan. Antifungal agents, such as echinocandins, voriconazole, liposomal amphotericin B, and posaconazole, which are indicated for invasive fungal infections, have been launched in Japan. As a result, the use of antifungal drugs for invasive fungal infections has been on the rise. It is thought that this is related to the increasing number of hosts with low immunity in Japan. Kawabe et al. [56] provided a detailed description of the trend of antifungal drugs used in Japan from 2006 to 2015 based on sales data as an alternative indicator of the trends in fungal infections. The total amount of antifungal drugs used decreased over time, and the main reason for this result was the decreasing use of antifungal drugs for superficial fungal infections. Interestingly, the use of antifungal agents for invasive fungal infections increased, and the total use of antifungal agents decreased $(\mathrm{r}=-0.057, p$ for trend $<0.0001)$. Oral and parenteral antifungals were significantly decreased by $44.1 \%(\mathrm{r}=-0.056, p$ for trend $<0.0001)$ and $27.1 \%(\mathrm{r}=-0.0012$, $p$ for trend $=0.00061$ ), respectively. The use of antifungal agents for superficial fungal infections was significantly decreased to $49.8 \%(\mathrm{r}=-0.061, p$ for trend $<0.0001)$. However, the use of antifungal agents for invasive fungal infections increased significantly to $19.9 \%$ $(\mathrm{r}=0.0032, p$ for trend $=0.00045)$. Among the parenteral antifungal drugs used for invasive fungal infections, echinocandins accounted for more than half.

\subsection{Antifungal Stewardship by Pharmacists in Japan}

The main objective of the antifungal stewardship programs (AFSPs) is to optimize the use of antifungal drugs by integrating the experience and knowledge of professionals to address issues that impede the appropriate use of antifungal drugs [57].

Hamdy et al. [58] offered suggestions for both process metrics (i.e., those that measure the effect of an intervention on antifungal use) and outcome metrics (i.e., those that 
measure the effect of an intervention on the resistance patterns and clinical outcomes) for antifungal stewardship. Table 1 was partially modified by the authors on the basis of these suggestions. Pharmacists play an important role in AFSPs, including optimizing the treatment in antifungal therapy.

Table 1. Suggestions for process and outcome indices for antifungal stewardship by pharmacists.

\begin{tabular}{|c|c|}
\hline Process Index & Examples of Index \\
\hline Antifungal drug consumption & $\begin{array}{l}\text { Days of therapy per } 1000 \text { patient-days, defined daily doses per } 1000 \text { patient-days, } \\
\text { or individual patients treated with antifungal drugs (excluded prophylaxis) }\end{array}$ \\
\hline Compliance with institutional guidelines & $\begin{array}{l}\text { Proportion of compliance using template of each facility for the following items } \\
\text { and confirmation }\end{array}$ \\
\hline Choice of drug & Proportion of patients treated with drug of choice for indication \\
\hline Dose & Approved indications and dosages of each country \\
\hline Administration period & $\begin{array}{l}\text { For fungaemia, administration for at least } 14 \text { days after negative confirmation of } \\
\text { blood culture }\end{array}$ \\
\hline Therapeutic drug monitoring & $\begin{array}{l}\text { Proportion of patients on azole and voriconazole/posaconazole for whom serum } \\
\text { level was checked appropriately from time of initiation }\end{array}$ \\
\hline Drug-drug interaction (DDI) & $\begin{array}{l}\text { Proportion of patients on azole for whom DDI was checked appropriately from } \\
\text { time of initiation }\end{array}$ \\
\hline Step-down & $\begin{array}{l}\text { Proportion of patients with fluconazole-sensitive Candida for whom therapy was } \\
\text { switched from broad-spectrum agent, polyene, or echinocandin to fluconazole and } \\
\text { intravenous to oral formulation }\end{array}$ \\
\hline Use of diagnostic tests & $\begin{array}{l}\text { Proportion of compliance with guideline recommendations for monitoring serum } \\
\text { galactomannan or }(1,3)-\beta \text {-d-glucan or novel approaches }\end{array}$ \\
\hline Source control & Proportion of patients with candidemia with catheter removal \\
\hline Outcome index & Examples of metric \\
\hline Treatment of invasive fungal infection & $\begin{array}{l}\text { Proportion of patients with clinical cure or proportion of patients with candidemia } \\
\text { with recurrent infection }\end{array}$ \\
\hline Resistance & Proportion of Candida isolates caused by fluconazole-resistant strains \\
\hline Cost & Total cost of prescriptions per year, stratified by antifungal drug \\
\hline
\end{tabular}

Antifungal stewardship considerations for adults and pediatrics. Virulence, 2017; 8(6):658-672 [58]. Partially modified by authors.

Kawaguchi et al. [59] reported that the patients who received systemic antifungal therapy from 2011 to 2016 were divided into pre-intervention and intervention groups, and the monthly average number of treatment days was significantly lower in the intervention group $(15.1 \pm 3.1$ vs. $12.7 \pm 4.3, p=0.009)$, and the cost of the antifungal therapeutics decreased by USD 260,520 (13.5\%) over three years. In addition, there was a downward trend in both the 30-day mortality and in-hospital mortality among the patients with candidiasis. The increased selection of antifungal agents by the AFSP interventions conducted in Japanese hospitals has resulted in lower antifungal drug usage and cost savings, demonstrating a tendency to improve the prognosis of the patients with candidemia.

As reported by a group of Japanese pharmacists, Samura et al. [60], the process parameter cumulative optimal use of antifungal drugs was significantly increased in the post-AFSP group $(p=0.025)$. In addition, the median number of days of antifungal treatment was 6.0 (interquartile range (IQR) 0.3-15.7) and the median 3.4 (IQR 1.9-3.4) per 1000 patient days, with a significant decrease in the post-AFSP group $(p<0.001)$. The outcome parameter expenditure on antifungal drugs was USD $9390.5 \pm 5687.1$ and USD $5930.8 \pm 4687.0$ before and after AFSPs, respectively, with a significant decrease in the post-AFSP group $(p=0.002)$.

We investigated the compliance with the standard dosage of voriconazole in our hospital (Figure 2) [61]. The data from an overall total of 118 patients who received 
voriconazole in our hospital from April 2015 to March 2019 were included. Of these, 26 patients whose voriconazole use was prophylactic were included, and 92 patients whose voriconazole use was therapeutic were included. The appropriate dose of voriconazole was a loading dose of 5 to $6 \mathrm{mg} / \mathrm{kg}$ twice daily, followed by a maintenance dose of 3 to $4 \mathrm{mg} / \mathrm{kg}$ twice daily. In the patients with hepatic dysfunction (Child-Pugh A-C), the maintenance dose was reduced to 1.5 to $2 \mathrm{mg} / \mathrm{kg}$. Since the dose was calculated based on body weight, it was considered appropriate to round the dose to within $10 \%$ of the recommended dose. Although the difference was not significant due to the small sample size, the rate of adherence to the standard dose of voriconazole in the prophylactic dose and the loading dose and maintenance dose in the treatment all improved as a result of the intervention of a pharmacist.

prophylactic administration

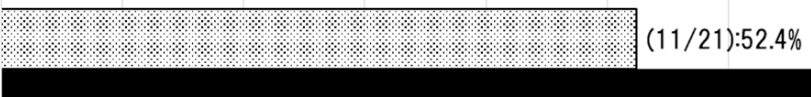

$(4 / 5): 80 \%$

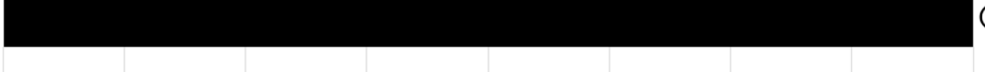

treatment / maintenance dose

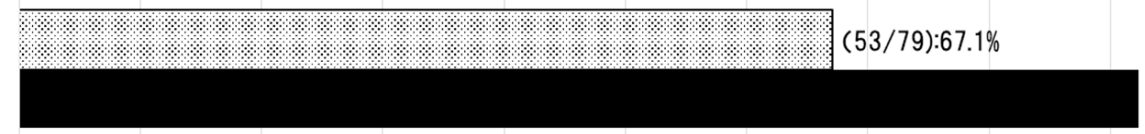

$(12 / 13): 92.3 \%$

treatment / loading dose

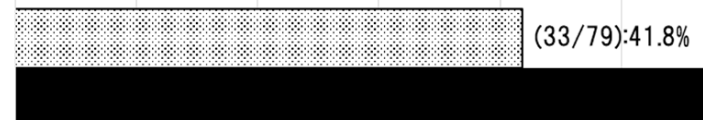

$(33 / 79): 41.8 \%$

treatment / loading dose

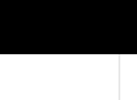

0

10

20

30

$40 \quad 50$

60

70

80

90

100

눙 2015.4-2018.3 2018.4-2019.3

Figure 2. The rate of adherence to the standard dose of voriconazole. The survey was conducted at our hospital between April 2015-March 2019. Overall, data from 118 patients were reported [61].

AMR Alliance Japan, a policy proposal announced in July 2019, proposes that items will be added, changed, or emphasized in the Japanese government's next National Action Plan on Antimicrobial Resistance to be implemented in 2021 [7]. The efforts are encouraged in this regard to promote an increase in the number of trained healthcare professionals to perform TDM. The TDM of voriconazole of the antifungal agent is associated with efficacy and safety, and pharmacists play a particularly important role in TDM [62,63]. Voriconazole concentration is associated with adverse effects, including visual symptoms, neuropathy, and hepatotoxicity [64-69].

Hamada et al. [70] used a previously unreported meta-analysis for the first time to investigate the optimal concentration of voriconazole. This result was published as a practical guideline for voriconazole TDM [71] and has been extensively clinically applied following a consensus review conducted by the Japan Society of Chemotherapy and the Japanese Society for Therapeutic Drug Monitoring. Subsequently, Hamada et al. [72] reported that, by observing the concentration with TDM of voriconazole, the pharmacist suggested a change in treatment after the onset of AEs, and most patients completed the treatment. This study enrolled a relatively large number of patients, 401, at five hospitals in Japan. Hepatotoxicity and visual symptoms were significantly correlated with the voriconazole trough concentration at the onset of AEs, and the trough cut-offs were $3.5 \mu \mathrm{g} / \mathrm{mL}$ for hepatotoxicity and $4.2 \mu \mathrm{g} / \mathrm{mL}$ for visual symptoms. As a great result, with the voriconazole dose adjustment based on TDM, the treatment was completed in $88.9 \%$ of the patients with hepatotoxicity and $96.4 \%$ of the patients with visual symptoms. 
In our latest study, Hanai et al. [73] conducted a systematic review and meta-analysis to assess the relationship between the voriconazole trough concentration and the efficacy and safety, and re-evaluated it in 2554 adult patients. Although further high-quality trials are needed, our findings recommend an appropriate target voriconazole trough concentration of $1.0-4.0 \mu \mathrm{g} / \mathrm{mL}$ for increased clinical success while minimizing toxicity. On the other hand, pediatric data are also important. However, data on the target range of voriconazole concentrations in children are lacking because most studies are limited by small sample sizes and other factors. Hanai et al. [74] used a similar approach to suggest that the target concentration range for voriconazole in children, particularly for Asian populations, is $1.0-3.0 \mu \mathrm{g} / \mathrm{mL}$.

As a recent topic, azole-resistant Aspergillus species [75,76] and azole-resistant Candida species [77] have become a problem. By standardizing the target concentration with TDM, pharmacists may be able to participate not only in efficacy and safety but also in the mechanism of resistance development.

In this article, AMR Alliance Japan also suggests that efforts should be made to promote an increase in the amount of therapeutic drug monitoring (TDM) in the Japanese government's next NAP on AMR [8]. Since the author is one of the members of the TDM guidelines board in Japan, we have summarized support for the antimicrobial stewardship program centered on TDM.

\section{Conclusions}

We reported on recent AMR strategies and studies conducted by Japanese pharmacists in the context of the COVID-19 pandemic. Pharmacists are an integral part of the antimicrobial stewardship team and must be actively involved in antimicrobial management. In Japan, the titles of board-certified infection control pharmacy specialist and infectious disease chemotherapy pharmacist exist. However, the staffing constraints that allow pharmacists to complete such programs in some hospitals in Japan and the shortage of ID-trained pharmacists are barriers to the implementation of the program and present challenges. Japanese pharmacists are working to reduce AMR and change the Japanese system while accumulating achievements one step at a time. Japanese pharmacists strive to properly utilize TDM as a tool to improve the adequacy of antimicrobial use. Further validation is needed in the future to discuss the use of a proactive TDM, defining the criteria that could identify the patients, the disease, or the conditions that are more often associated with pharmacokinetic variability. It should be noted that this review does not include a wider approach. A wider approach to antimicrobial stewardship that includes other professionals working in the ICU, infectious disease wards, cardio-surgery units, etc., for whom the possibility of spreading knowledge about the risk of multi-resistant strains and protocols to reduce the risk is of fundamental importance [78]. Pharmacists can play a role in controlling AMR by actively incorporating TDM and PK/PD theories that utilize specialized pharmacokinetics.

Author Contributions: Conceptualization, Y.H.; writing - original draft preparation, Y.H., F.E. and K.K.; writing-review and editing, Y.H., F.E. and K.K. All authors have read and agreed to the published version of the manuscript.

Funding: This research received no external funding.

Institutional Review Board Statement: Not applicable.

Informed Consent Statement: Not applicable.

Data Availability Statement: All data are applicable in the paper.

Conflicts of Interest: The authors declare no conflict of interest. 


\section{References}

1. World Health Organization. Global Action Plan on Antimicrobial Resistance. 2015. Available online: https://www.who.int/ antimicrobial-resistance/global-action-plan/en/ (accessed on 11 August 2021).

2. World Health Organization. Global Action Plan on Antimicrobial Resistance. 2020. Available online: https://www.who.int/ antimicrobial-resistance/publications/global-action-plan/en/ (accessed on 11 August 2021).

3. World Health Organization. Country Self Assessment in Global Database for Antimicrobial Resistance. 2020. Available online: https: / / amrcountryprogress.org/ (accessed on 11 August 2021).

4. The Government of Japan. NAP on Antimicrobial Resistance (AMR) 2016-2020. 2020. Available online: https://www.mhlw.go. jp / file/06-Seisakujouhou-10900000-Kenkoukyoku/0000138942.pdf (accessed on 11 August 2021).

5. Muraki, Y.; Yagi, T.; Tsuji, Y.; Nishimura, N.; Tanabe, M.; Niwa, T.; Watanabe, T.; Fujimoto, S.; Takayama, K.; Murakami, N.; et al. Japanese antimicrobial consumption surveillance: First report on oral and parenteral antimicrobial consumption in Japan (2009-2013). J. Glob. Antimicrob. Resist. 2016, 7, 19-23. [CrossRef]

6. Ebihara, F.; Hamada, Y.; Maruyama, T.; Nakamura, S.; Takahashi, S.; Hasegawa, Y.; Konishi, T.; Mitsuda, T.; Kikuchi, K.; Kimura, T. Outpatient use of oral antibiotics and initiatives for appropriate use. Jpn. J. Chemother. 2021, 69, 392-397.

7. Brody, H. Medicine's ethical responsibility for health care reform-The Top Five list. N. Engl. J. Med. 2010, 362, 283-285. [CrossRef]

8. AMR Alliance Japan. Recommendations toward the Next National Action Plan on Antimicrobial Resistance. Available online: https://hgpi.org/en/wp-content/uploads/sites/2/Action_Plan_Recommendations_ENG.pdf (accessed on 11 August 2021).

9. Uematsu, H.; Yamashita, K.; Kunisawa, S.; Fushimi, K.; Imanaka, Y. The economic burden of methicillin-resistant Staphylococcus aureus in community-onset pneumonia inpatients. Am. J. Infect. Control 2016, 44, 1628-1633. [CrossRef]

10. Ministry of Health, Labour and Welfare. Japan Nosocomial Infections Surveillance Clinical Laboratory Division [CLSI 2012 Version]. Available online: https://janis.mhlw.go.jp/english/report/open_report/2020/3/1/ken_Open_Report_Eng_202000 _clsi2012.pdf (accessed on 11 August 2021).

11. Tsuzuki, S.; Matsunaga, N.; Yahara, K.; Gu, Y.; Hayakawa, K.; Hirabayashi, A.; Kajihara, T.; Sugai, M.; Shibayama, K.; Ohmagari, N. National trend of blood-stream infection attributable deaths caused by Staphylococcus aureus and Escherichia coli in Japan. J. Infect. Chemother. 2020, 26, 367-371. [CrossRef]

12. Tsuzuki, S.; Matsunaga, N.; Yahara, K.; Shibayama, K.; Sugai, M.; Ohmagari, N. Disease burden of bloodstream infections caused by antimicrobial-resistant bacteria: A population-level study, Japan, 2015-2018. Int. J. Infect. Dis. 2021, 108, 119-124. [CrossRef] [PubMed]

13. Murray, C.J.; Lopez, A.D. The utility of DALYs for public health policy and research: A reply. Bull. World Health Organ. 1997, 75, 377-381. [PubMed]

14. Cassini, A.; Högberg, L.D.; Plachouras, D.; Quattrocchi, A.; Hoxha, A.; Simonsen, G.S.; Colomb-Cotinat, M.; Kretzschmar M.E.; Devleesschauwer, B.; Cecchini, M.; et al. Attributable deaths and disability-adjusted life-years caused by infections with antibiotic-resistant bacteria in the EU and the European Economic Area in 2015: A population-level modelling analysis. Lancet Infect. Dis 2019, 19, 56-66. [CrossRef]

15. Uematsu, H.; Yamashita, K.; Mizuno, S.; Kunisawa, S.; Shibayama, K.; Imanaka, Y. Effect of methicillin-resistant Staphylococcus aureus in Japan. Am. J. Infect. Control. 2018, 46, 1142-1147. [CrossRef]

16. Japanese Society of Chemotherapy/Japanese Association for Infectious Diseases. Practical Guidelines for the Management and Treatment of Infections Caused by MRSA (In Japanese). 2019. Available online: http:/ / www.chemotherapy.or.jp/guideline/ guideline_mrsa_2019.html (accessed on 18 October 2021).

17. Goto, R.; Inose, R.; Kusama, Y.; Kawabe, A.; Ishii, S.; Ebisui, A.; Ishikane, M.; Yagi, T.; Ohmagari, N.; Muraki, Y. Trends of the Use of Anti-methicillin-Resistant Staphylococcus aureus Agents in Japan Based on Sales Data from 2006 to 2015. Biol. Pharm. Bull. 2020, 43, 1906-1910. [CrossRef]

18. Hansen, S.; Schwab, F.; Asensio, A.; Carsauw, H.; Heczko, P.; Klavs, I.; Lyytikäinen, O.; Palomar, M.; Riesenfeld-Orn, I.; Savey, A.; et al. Methicillin-resistant Staphylococcus aureus (MRSA) in Europe: Which infection control measures are taken? Infection 2010, 38, 159-164. [CrossRef]

19. Kim, Y.C.; Kim, M.H.; Song, J.E.; Ahn, J.Y.; Oh, D.H.; Kweon, O.M.; Lee, D.; Kim, S.B.; Kim, H.W.; Jeong, S.J.; et al. Trend of methicillin-resistant Staphylococcus aureus (MRSA) bacteremia in an institution with a high rate of MRSA after the reinforcement of antibiotic stewardship and hand hygiene. Am. J. Infect. Control 2013, 41, e39-e43. [CrossRef]

20. Johnson, P.D.; Martin, R.; Burrell, L.J.; Grabsch, E.A.; Kirsa, S.W.; O’Keeffe, J.; Mayall, B.C.; Edmonds, D.; Barr, W.; Bolger, C.; et al. Efficacy of an alcohol/chlorhexidine hand hygiene program in a hospital with high rates of nosocomial methicillin-resistant Staphylococcus aureus (MRSA) infection. Med. J. Aust. 2005, 183, 509-514. [CrossRef]

21. MacDonald, A.; Dinah, F.; MacKenzie, D.; Wilson, A. Performance feedback of hand hygiene, using alcohol gel as the skin decontaminant, reduces the number of inpatients newly affected by MRSA and antibiotic costs. J. Hosp. Infect. 2004, $56,56-63$. [CrossRef]

22. Aldeyab, M.A.; Scott, M.G.; Kearney, M.P.; Alahmadi, Y.M.; Magee, F.A.; Conlon, G.; McElnay, J.C. Impact of an enhanced antibiotic stewardship on reducing methicillin-resistant Staphylococcus aureus in primary and secondary healthcare settings. Epidemiol. Infect. 2014, 142, 494-500. [CrossRef] [PubMed] 
23. Lawes, T.; López-Lozano, J.M.; Nebot, C.; Macartney, G.; Subbarao-Sharma, R.; Dare, C.R.; Edwards, G.F.; Gould, I.M. Turning the tide or riding the waves? Impacts of antibiotic stewardship and infection control on MRSA strain dynamics in a Scottish region over 16 years: Non-linear time series analysis. BMJ Open 2015, 5, e006596. [CrossRef] [PubMed]

24. Niwa, T.; Shinoda, Y.; Suzuki, A.; Ohmori, T.; Yasuda, M.; Ohta, H.; Fukao, A.; Kitaichi, K.; Matsuura, K.; Sugiyama, T.; et al. Outcome measurement of extensive implementation of antimicrobial stewardship in patients receiving intravenous antibiotics in a Japanese university hospital. J. Clin. Pract. 2012, 66, 999-1008. [CrossRef]

25. Ohashi, K.; Matsuoka, T.; Shinoda, Y.; Fukami, Y.; Shindoh, J.; Yagi, T.; Yoshimura, T.; Sugiyama, T. Evaluation of treatment outcomes of patients with MRSA bacteremia following antimicrobial stewardship programs with pharmacist intervention. Int. J. Clin. Pract. 2018, 72, e13065. [CrossRef] [PubMed]

26. Rybak, M.J.; Le, J.; Lodise, T.P.; Levine, D.P.; Bradley, J.S.; Liu, C.; Mueller, B.A.; Pai, M.P.; Wong-Beringer, A.; Rotschafer, J.C.; et al Therapeutic Monitoring of Vancomycin for Serious Methicillin-resistant Staphylococcus aureus Infections: A Revised Consensus Guideline and Review by the American Society of Health-system Pharmacists, the Infectious Diseases Society of America, the Pediatric Infectious Diseases Society, and the Society of Infectious Diseases Pharmacists. Clin. Infect. Dis. 2020, 71, 1361-1364.

27. Suzuki, A.; Hamada, Y.; Ikeda, H.; Tanaka, H.; Yanagihara, M.; Namiki, M.; Watanabe, T.; Sasaki, T. Comparison of trough concentration and area under the curve of vancomycin associated with the incidence of nephrotoxicity and predictors of a high trough level. J. Infect. Chemother. 2021, 27, 455-460. [CrossRef]

28. Hashimoto, N.; Kimura, T.; Hamada, Y.; Niwa, T.; Hanai, Y.; Chuma, M.; Fujii, S.; Matsumoto, K.; Shigemi, A.; Kawamura, H.; et al. Candidates for area under the time-concentration curve-guided dosing and risk reduction based on analyses of risk factors associated with nephrotoxicity in vancomycin-treated patients. J. Glob. Antimicrob. Resist. 2021, 27, 12-19. [CrossRef] [PubMed]

29. Ferri, M.; Ranucci, E.; Romagnoli, P.; Giaccone, V. Antimicrobial resistance: A global emerging threat to public health systems. Crit. Rev. Food Sci. Nutr. 2017, 57, 2857-2876. [CrossRef] [PubMed]

30. Willyard, C. The drug-resistant bacteria that pose the greatest health threats. Nature 2017, 543, 15. [CrossRef] [PubMed]

31. Woerther, P.L.; Burdet, C.; Chachaty, E.; Andremont, A. Trends in human fecal carriage of extended-spectrum $\beta$-lactamases in the community: Toward the globalization of CTX-M. Clin. Microbiol. Rev. 2013, 26, 744-758. [CrossRef]

32. Chong, Y.; Shimoda, S.; Shimono, N. Current epidemiology, genetic evolution and clinical impact of extended-spectrum $\beta$ lactamase-producing Escherichia coli and Klebsiella pneumoniae. Infect. Genet. Evol. 2018, 61, 185-188. [CrossRef] [PubMed]

33. Miyazaki, M.; Yamada, Y.; Matsuo, K.; Komiya, Y.; Uchiyama, M.; Nagata, N.; Takata, T.; Jimi, S.; Imakyure, O. Change in the Antimicrobial Resistance Profile of Extended-Spectrum $\beta$-Lactamase-Producing Escherichia coli. J. Clin. Med. Res. 2019, 11, 635-641. [CrossRef]

34. Amann, S.; Neef, K.; Kohl, S. Antimicrobial resistance (AMR). Eur. J. Hosp. Pharm. 2019, 26, 175-177. [CrossRef]

35. FAO. The FAO Action Plan on Antimicrobial Resistance 2016-2020. Available online: http://www.fao.org/3/a-i5996e.pdf (accessed on 11 August 2021).

36. Nishiyama, M.; Praise, S.; Tsurumaki, K.; Baba, H.; Kanamori, H.; Watanabe, T. Prevalence of Antibiotic-Resistant Bacteria ESKAPE among Healthy People Estimated by Monitoring of Municipal Wastewater. Antibiotics 2021, 10, 495. [CrossRef]

37. Harris, P.N.A.; Tambyah, P.A.; Lye, D.C.; Mo, Y.; Lee, T.H.; Yilmaz, M.; Alenazi, T.H.; Arabi, Y.; Falcone, M.; Bassetti, M.; et al. Effect of piperacillin-tazobactam vs. meropenem on 30-day mortality for patients with E. coli or Klebsiella pneumoniae bloodstream infection and ceftriaxone resistance: A randomized clinical trial. JAMA 2018, 320, 984-994. [CrossRef]

38. Doi, Y. Treatment Options for Carbapenem-resistant Gram-negative Bacterial Infections. Clin. Infect. Dis. 2019, 69, S565-s575. [CrossRef]

39. Wada, K.; Yokoyama, T.; Uno, S.; Araki, M.; Sadahira, T.; Maruyama, Y.; Acosta, H.; Nakajima, H.; Hiyama, Y.; Kunishima, Y.; et al. Nationwide surveillance of bacterial pathogens isolated from patients with acute uncomplicated cystitis in 2018: Conducted by the Japanese Research Group for Urinary Tract Infections (JRGU). J. Infect. Chemother. 2021, 27, 1169-1180. [CrossRef]

40. Nakai, H.; Hagihara, M.; Kato, H.; Hirai, J.; Nishiyama, N.; Koizumi, Y.; Sakanashi, D.; Suematsu, H.; Yamagishi, Y.; Mikamo, $\mathrm{H}$. Prevalence and risk factors of infections caused by extended-spectrum $\beta$-lactamase (ESBL)-producing Enterobacteriaceae. J. Infect. Chemother. 2016, 22, 319-326. [CrossRef]

41. Tulara, N.K. Nitrofurantoin and Fosfomycin for Extended Spectrum Beta-lactamases Producing Escherichia coli and Klebsiella pneumoniae. J. Glob. Infect. Dis. 2018, 10, 19-21. [CrossRef]

42. Fleming-Dutra, K.E.; Hersh, A.L.; Shapiro, D.; Bartoces, M.; Enns, E.A.; File, T.M., Jr.; Finkelstein, J.A.; Gerber, J.S.; Hyun, D.Y.; Linder, J.A.; et al. Prevalence of Inappropriate Antibiotic Prescriptions among US Ambulatory Care Visits, 2010-2011. JAMA 2016, 315, 1864-1873. [CrossRef]

43. Doron, S.; Davidson, L.E. Antimicrobial stewardship. Mayo Clin. Proc. 2011, 86, 1113-1123. [CrossRef]

44. Kusama, Y.; Tsuzuki, S.; Muraki, Y.; Koizumi, R.; Ishikane, M.; Ohmagari, N. The effects of Japan's National Action Plan on Antimicrobial Resistance on antimicrobial use. Int. J. Infect. Dis. 2021, 103, 154-156. [CrossRef] [PubMed]

45. Kato, T.; Tanaka, I.; Seyama, Y.; Sekikawa, R.; Suzuki, S.; Nagasawa, M.; Hino, S. The effectiveness of prescription support and treatment reporting system on the appropriate usage of oral third-generation cephalosporins. J. Infect. Chemother. 2021, 27, 419-423. [CrossRef] [PubMed]

46. World Health Organization. WHO Publishes List of Bacteria for Which New Antibiotics Are Urgently Needed. Available online: https: / / www.who.int/news-room/detail/27-02-2017-who-publishes-list-of-bacteria-for-which-new-antibiotics-areurgently-needed (accessed on 1 August 2021). 
47. Matsumura, Y.; Yamamoto, M.; Nagao, M.; Tanaka, M.; Takakura, S.; Ichiyama, S. In vitro activities and detection performances of cefmetazole and flomoxef for extended-spectrum $\beta$-lactamase and plasmid-mediated AmpC $\beta$-lactamase-producing Enterobacteriaceae. Diagn. Microbiol. Infect. Dis. 2016, 84, 322-327. [CrossRef] [PubMed]

48. Matsumura, Y.; Yamamoto, M.; Nagao, M.; Komori, T.; Fujita, N.; Hayashi, A.; Shimizu, T.; Watanabe, H.; Doi, S.; Tanaka, M.; et al. Multicenter retrospective study of cefmetazole and flomoxef for treatment of extended-spectrum-beta-lactamase-producing Escherichia coli bacteremia. Antimicrob. Agents Chemother. 2015, 59, 5107-5113. [CrossRef]

49. Tashiro, S.; Hayashi, M.; Takemura, W.; Igarashi, Y.; Liu, X.; Mizukami, Y.; Kojima, N.; Enoki, Y.; Taguchi, K.; Yokoyama, Y.; et al. Pharmacokinetics/Pharmacodynamics Evaluation of Flomoxef against Extended-Spectrum Beta-Lactamase-Producing Escherichia coli In Vitro and In Vivo in a Murine Thigh Infection Model. Pharm. Res. 2021, 38, 27-35. [CrossRef]

50. Doi, A.; Shimada, T.; Harada, S.; Iwata, K.; Kamiya, T. The efficacy of cefmetazole against pyelonephritis caused by extendedspectrum beta-lactamase-producing Enterobacteriaceae. Int. J. Infect. Dis. 2013, 17, e159-e163. [CrossRef] [PubMed]

51. Fukuchi, T.; Iwata, K.; Kobayashi, S.; Nakamura, T.; Ohji, G. Cefmetazole for bacteremia caused by ESBL-producing enterobacteriaceae comparing with carbapenems. BMC Infect. Dis. 2016, 16, 427. [CrossRef]

52. Hamada, Y.; Matsumura, Y.; Nagashima, M.; Akazawa, T.; Doi, Y.; Hayakawa, K. Retrospective evaluation of appropriate dosing of cefmetazole for invasive urinary tract infection due to extended-spectrum $\beta$-lactamase-producing Escherichia coli. J. Infect. Chemother. 2021, 27, 1602-1606. [CrossRef] [PubMed]

53. Wisplinghoff, H.; Bischoff, T.; Tallent, S.M.; Seifert, H.; Wenzel, R.P.; Edmond, M.B. Nosocomial bloodstream infections in US hospitals: Analysis of 24,179 cases from a prospective nationwide surveillance study. Clin. Infect. Dis. 2004, 39, 309-317. [CrossRef]

54. Kakeya, H.; Yamada, K.; Kaneko, Y.; Yanagihara, K.; Tateda, K.; Maesaki, S.; Takesue, Y.; Tomono, K.; Kadota, J.I.; Kaku, M.; et al. National Trends in the Distribution of Candida Species Causing Candidemia in Japan from 2003 to 2014. Med. Mycol. J. 2018, 59, E19-E22. [CrossRef]

55. Kishimoto, K.; Kasai, M.; Kawamura, N.; Ito, Y.; Yoshida, M.; Hasegawa, D.; Kawasaki, K.; Kosaka, Y. Clinical features in proven and probable invasive fungal disease in children and adolescents at a pediatric referral center: A 5-year experience. World J. Pediatr. 2019, 15, 270-275. [CrossRef] [PubMed]

56. Kawabe, A.; Muraki, Y.; Inose, R.; Kusama, Y.; Goto, R.; Ebisui, A.; Ishii, S.; Ishikane, M.; Ohge, H.; Ohmagari, N.; et al. Trends of Antifungal Use Based on Sales Data in Japan from 2006 to 2015. Biol. Pharm. Bull. 2020, 43, 1248-1252. [CrossRef]

57. Agrawal, S.; Barnes, R.; Brüggemann, R.J.; Rautemaa-Richardson, R.; Warris, A. The role of the multidisciplinary team in antifungal stewardship. J. Antimicrob. Chemother. 2016, 71, ii37-ii42. [CrossRef]

58. Hamdy, R.F.; Zaoutis, T.E.; Seo, S.K. Antifungal stewardship considerations for adults and pediatrics. Virulence 2017, 8, 658-672. [CrossRef] [PubMed]

59. Kawaguchi, H.; Yamada, K.; Imoto, W.; Yamairi, K.; Shibata, W.; Namikawa, H.; Yoshii, N.; Nakaie, K.; Okada, Y.; Fujita, A.; et al. The effects of antifungal stewardship programs at a tertiary-care teaching hospital in Japan. J. Infect. Chemother. 2019, $25,458-462$. [CrossRef] [PubMed]

60. Samura, M.; Hirose, N.; Kurata, T.; Ishii, J.; Nagumo, F.; Takada, K.; Koshioka, S.; Uchida, M.; Yamamoto, S.; Inoue, J.; et al. Support for fungal infection treatment mediated by pharmacist-led antifungal stewardship activities. J. Infect. Chemother. 2020, 26, 272-279. [CrossRef]

61. Hamada, Y.; Ebihara, F.; Kimura, T.; Kikuchi, K. In Proceedings of the 63th Annual Meeting of the Japanese Society for Medical Mycology, Chiba, Japan, 29 October 2019. Available online: https://www.mycology-jp.org/en/ (accessed on 11 August 2021).

62. Walsh, T.J.; Anaissie, E.J.; Denning, D.W.; Herbrecht, R.; Kontoyiannis, D.P.; Marr, K.A.; Morrison, V.A.; Segal, B.H.; Steinbach, W.J.; Stevens, D.A.; et al. Treatment of aspergillosis: Clinical practice guidelines of the Infectious Diseases Society of America. Clin. Infect. Dis. 2008, 46, 327-360. [CrossRef]

63. Ullmann, A.J.; Akova, M.; Herbrecht, R.; Viscoli, C.; Arendrup, M.C.; Arikan-Akdagli, S.; Bassetti, M.; Bille, J.; Calandra, T.; Castagnola, E.; et al. ESCMID guideline for the diagno-sis and management of Candida diseases 2012: Adults with haematological malignancies and after haematopoietic stem cell transplantation (HCT). Clin. Microbiol. Infect. 2012, 18 (Suppl. 7), 53-67. [CrossRef]

64. Saito, T.; Fujiuchi, S.; Tao, Y.; Sasaki, Y.; Ogawa, K.; Suzuki, K.; Tada, A.; Kuba, M.; Kato, T.; Kawabata, M.; et al. Efficacy and safety of voriconazole in the treatment of chronic pulmonary aspergillosis: Experience in Japan. Infection 2012, 40, 661-667. [CrossRef] [PubMed]

65. Luong, M.L.; Hosseini-Moghaddam, S.M.; Singer, L.G.; Chaparro, C.; Azad, S.; Lazar, N.; Boutros, P.C.; Keshavjee, S.; Rotstein, C.; Husain, S. Risk factors for voriconazole hepatotoxicity at 12 weeks in lung transplant recipients. Am. J. Transpl. 2012, 12, 1929-1935. [CrossRef] [PubMed]

66. Zonios, D.I.; Gea-Banacloche, J.; Childs, R.; Bennett, J.E. Hallucinations during voriconazole therapy. Clin. Infect. Dis. 2008, 47, e7-e10. [CrossRef] [PubMed]

67. Imhof, A.; Schaer, D.J.; Schanz, U.; Schwarz, U. Neurological adverse events to voriconazole: Evidence for therapeutic drug monitoring. Swiss Med. Wkly. 2006, 136, 739-742. [CrossRef]

68. Boyd, A.E.; Modi, S.; Howard, S.J.; Moore, C.B.; Keevil, B.G.; Denning, D.W. Adverse reactions to voriconazole. Clin. Infect. Dis. 2004, 39, 1241-1244. [CrossRef] 
69. Walsh, T.J.; Pappas, P.; Winston, D.J.; Lazarus, H.M.; Petersen, F.; Raffalli, J.; Yanovich, S.; Stiff, P.; Greenberg, R.; Donowitz, G.; et al. Voriconazole compared with liposomal amphotericin B for empirical antifungal therapy in patients with neutropenia and persistent fever. N. Engl. J. Med. 2002, 346, 225-234. [CrossRef] [PubMed]

70. Hamada, Y.; Seto, Y.; Yago, K.; Kuroyama, M. Investigation and threshold of optimum blood concentration of voriconazole: A descriptive statistical meta-analysis. J. Infect. Chemother. 2012, 18, 501-507. [CrossRef]

71. Hamada, Y.; Tokimatsu, I.; Mikamo, H.; Kimura, M.; Seki, M.; Takakura, S.; Ohmagari, N.; Takahashi, Y.; Kasahara, K.; Matsumoto, K.; et al. Practice guidelines for therapeutic drug monitoring of voriconazole: A consensus review of the Japanese Society of Chemotherapy and the Japanese Society of Therapeutic Drug Monitoring. J. Infect. Chemother. 2013, 19, 381-392. [CrossRef] [PubMed]

72. Hamada, Y.; Ueda, T.; Miyazaki, Y.; Nakajima, K.; Fukunaga, K.; Miyazaki, T.; Nakada-Motokawa, N.; Nagao, M.; Kawamura, H.; Shigemi, A.; et al. Effects of antifungal stewardship using therapeutic drug monitoring in voriconazole therapy on the prevention and control of hepatotoxicity and visual symptoms: A multicentre study con-ducted in Japan. Mycoses 2020, 63, 779-786. [CrossRef] [PubMed]

73. Hanai, Y.; Hamada, Y.; Kimura, T.; Matsumoto, K.; Takahashi, Y.; Fujii, S.; Nishizawa, K.; Miyazaki, Y.; Takesue, Y. Favorable Effects of Voriconazole Trough Concentrations Exceeding $1 \mu \mathrm{g} / \mathrm{mL}$ on Treatment Success and All-Cause Mortality: A Systematic Review and Meta-Analysis. J. Fungi 2021, 7, 306. [CrossRef] [PubMed]

74. Hanai, Y.; Hamada, Y.; Kimura, T.; Matsumoto, K.; Takahashi, Y.; Fujii, S.; Nishizawa, K.; Takesue, Y. Optimal trough concentration of voriconazole with therapeutic drug monitoring in children: A systematic re-view and meta-analysis. J. Infect. Chemother. 2020, 27, 151-160. [CrossRef] [PubMed]

75. Simon, L.; Déméautis, T.; Dupont, D.; Kramer, R.; Garnier, H.; Durieu, I.; Sénéchal, A.; Reix, P.; Couraud, S.; Devouassoux, G.; et al. Azole resistance in Aspergillus fumigatus isolates from respiratory specimens in Lyon University Hospitals, France: Prevalence and mechanisms involved. Int. J. Antimicrob. Agents 2021, Online ahead of print. [CrossRef] [PubMed]

76. Tashiro, M.; Izumikawa, K.; Hirano, K.; Ide, S.; Mihara, T.; Hosogaya, N.; Takazono, T.; Morinaga, Y.; Nakamura, S.; Kurihara, S.; et al. Correlation between triazole treatment history and susceptibility in clinically isolated Aspergillus fumigatus. Antimicrob. Agents Chemother. 2012, 56, 4870-4875. [CrossRef] [PubMed]

77. Chen, P.Y.; Chuang, Y.C.; Wu, U.I.; Sun, H.Y.; Wang, J.T.; Sheng, W.H.; Chen, Y.C.; Chang, S.C. Mechanisms of Azole Resistance and Trailing in Candida tropicalis Bloodstream Isolates. J. Fungi 2021, 7, 612. [CrossRef] [PubMed]

78. Finazzi, S.; Paci, G.; Antiga, L.; Brissy, O.; Carrara, G.; Crespi, D.; Csato, G.; Csomos, A.; Duek, O.; Facchinetti, S.; et al. PROSAFE: A European endeavor to improve quality of critical care medicine in seven countries. Minerva Anestesiol 2020, 86, 1305-1320. [CrossRef] [PubMed] 